\title{
The Application of Smart Medical Care in Community Health Maintenance from User Experience: A Preliminary Study in College Students
}

\author{
Hsieh CHIA-JUNG ${ }^{\mathrm{a}, 1}$, Hsu TZU-CHI ${ }^{\mathrm{b}}$ and Hsu PEI-CHANG ${ }^{\mathrm{c}}$ \\ ${ }^{a}$ Department of Nursing, National Taipei University of \\ Nursing and Health Sciences, Taiwan, ROC \\ ${ }^{\mathrm{b}}$ Department of Computer Science and Information Enginerring, \\ National Ilan University, Taiwan, ROC \\ ' Pacy Tech Service Inc., Taiwan, ROC
}

\begin{abstract}
The aim of this study was to explore the students' perception of the development of smart healthcare, especially the experience of using $3 \mathrm{C}$ products in the maintenance of personal health. This helps us understand the capacity health managers should be endowed with in the modern era of smart medicine. And, we unraveled the college students' subjective feelings about using APP in health. Our results provide references for incorporating health maintenance platform resources into basic healthcare curriculums.
\end{abstract}

Keywords. Smart healthcare, community health maintenance, user experience

\section{Introduction}

In response to population aging, cross-disciplinary knowledge of smart healthcare and health applications should be implemented in the healthcare education. Curriculum focused on innovation, creativity and entrepreneurship will facilitate interdisciplinary cooperation in community care, and we should put more emphasis on such concepts in basic curriculums[1]. However, little is known about the college students' experiences in the application of smart medicine in the development of community health industry.

\section{Purpose}

To explore the students' perception of the development of smart healthcare, especially the experience of using $3 \mathrm{C}$ products in the maintenance of personal health.

${ }^{1}$ Corresponding Author, Hsieh Chia-Jung, No. 365, Ming-te Road, Peitou District, Taipei City, 11219, Taiwan, ROC; E-mail: chiajung@ntunhs.edu.tw. 


\section{Methods}

Students who have completed health maintenance curriculum in a domestic university of nursing and health sciences in Taiwan were enrolled in this study. Qualitative analysis was carried out through literature search and the students' learning text for the course in smart medicine application in health maintenance behavior. Meaningful data was extracted for further inductive content analysis.

\section{Results}

Qualitative results: Five categories of students' experiences of community health maintenance were obtained via theme extraction from the open answers to the survey questions. The pros are two themes, and the cons are four themes (Figure 1).

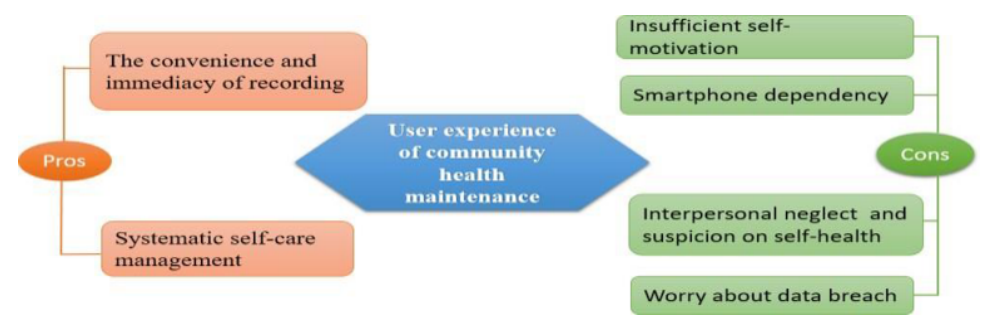

Figure 1. The pros and the cons of user experience.

Quantitative results: the most common experience the participants have with health maintenance by cell phone is the recording of exercise, followed by menstrual cycle. And from most of the participants' point of view, the advantages of using APP for health management overweigh their disadvantages.

\section{Conclusion}

Here we unraveled the college students' subjective feelings about using APP in personal health maintenance. Our results provide references for incorporating health maintenance platform resources and APP technology into basic healthcare curriculums for the cultivation of health maintenance knowledge and the capacity of interdisciplinary cooperation in the future.

\section{Acknowledgements}

We thank all the subjects for their valuable experience 


\section{References}

[1] Ahonen $\mathrm{O}$ et al. (2018). Identifying biomedical and health informatics competencies in higher education curricula, data, informatics and technology: An inspiration for improved healthcare. 